(RESEARCH ARTICLE)

\title{
Possible use of Spirulina and Klamath algae as biostimulants in Portulaca grandiflora (Moss Rose)
}

\author{
Domenico Prisa * \\ CREA Research Centre for Vegetable and Ornamental Crops, Council for Agricultural Research and Economics, Via dei \\ Fiori 8, 51012 Pescia, PT, Italy.
}

Publication history: Received on 20 August 2019; revised on 03 September 2019; accepted on 09 September 2019

Article DOI: https://doi.org/10.30574/wjarr.2019.3.2.0053

\begin{abstract}
The aim of the experiment was to evaluate the use and influence of Spirulina and Klamath algae on the growth, flowering, germination and mineral absorption of Portulaca grandiflora plants. The 3 experimental groups in cultivation were: (1) group without algae (CTRL), irrigated with water and previously fertilized substrate; (2) spirulina group (SPR) and fertilized substrate; (3) Klamath group (KLT) and fertilized substrate. The test showed a significant increase in the agronomic parameters analysed in plants treated with Spirulina and Klamath algae. In fact, all plants treated with (SPR and KLT) showed a significant increase in plant height and number of stems, number and diameter of flowers, vegetative and roots weight, number of leaves and flowering time. The test showed that the use of Spirulina and Klamath in the culture medium can significantly influence the germination of the Portulaca grandiflora and resulted in a significant increase in chlorophyll content and improved absorption of NPK. These results could be of interest to growers who want to improve the quality of their ornamental crops by using products that are easy to manage and not harmful to the environment.
\end{abstract}

Keywords: Succulent; Plant nutrition; Algae; Root growth; Abiotic stress; Biological fertility

\section{Introduction}

The Portulaca (Moss Rose) includes about 200 species of herbaceous plants, almost all of them succulent, with fleshy stems and leaves, of a more or less dark green colour. They can be annual or perennial and with an erect or prostrate posture [1-2]. They have flat or cylindrical leaves, which often have a tuft of hair at the base. The flowers, which have five petals, which can assume a variable colouration from the yellow to the pink to the purple to the red, are followed by capsule fruits, containing several small seeds [3]. Coming from Brazil, Argentina and Uruguay, this succulent species, with reddish stems, semi-prostrate and leaves, of bright green colour, with cylindrical section (long up to 2,5 $\mathrm{cm}$.), can grow up to $15-20 \mathrm{~cm}$. of height and about $15 \mathrm{~cm}$. of width. From June to September, it produces flowers, single or double, cup-shaped, with petals, shiny like the satin, varying in colour from yellow to red to purple, which open only in full sun, to close at sunset or in the shade. In October, flowering is followed by the appearance of conical capsules, containing many small seeds. On the market, there are numerous varieties with single, double, extra-double, solitary or grouped flowers, with petals of variable colour from the white to the yellow, from the pink to the red, from the orange to the crimson, from the scarlet red to the purple red [4-6].

Spirulina is a blue-green micro algae native to Central America and Central Africa, which grows wild in salt lakes characterized by alkaline and hot waters (such as Lake Texcoco, Lake Chad, etc.) [7]. Known since ancient times by the peoples of the tropical region, it is considered an excellent natural food supplement. Spirulina is characterized by a protein content, which varies between 55 and $77 \%$ of the dry weight. Among the other important nutrients of spirulina are: unsaturated fatty acids (linoleic acid, alpha-linolenic acid, gamma-linolenic acid, stearidonic acid,

\footnotetext{
${ }^{*}$ Corresponding author

E-mail address: domenico.prisa@crea.gov.it
} 
docosahexaenoic acid, arachidonic acid and eicosapentaenoic acid); plant pigments (beta-carotene, chlorophyll A, xanthophylls, myxoxanthophylls, zeaxanthin, echinenone, hydroxyechinenone, diatoxanthin, beta-cryptoxanthin, canthaxanthin edoscillaxanthin); phicobiliproteins (phycocyanin, allophocyanin); vitamins A, D, E, C, B1, B2, B3, B6, B9; mineral salts and trace elements (potassium, calcium, iron, copper, chromium, magnesium, manganese, phosphorus, sodium, selenium and zinc) [8].

The environmental and climatic conditions in which the Aphanizomenon of Lake Klamath grows are absolutely unique. The Klamath is a virtually untouched lake, nestled in a volcanic region from which receives rivers and streams dense with volcanic material, and with a bottom whose deposits of bioavailable minerals reach even up to $10 \mathrm{~m}$. in height. The Klamath is part of a nature conservation area. The only city that faces on the extreme southern edge of the lake, and discharges into a channel that comes out of the lake and goes to the sea. The lake Klamath is located on a plateau at $1300 \mathrm{~m}$. height, in a pre-desert area. Its climate combines the following 300 days of sunshine a year, with exceptional photosynthetic opportunities; and cold winters that force algae to produce very important essential fatty acids Omega 3 and 6 . Klamath is the only nutritional source containing the full spectrum of minerals and trace elements [9].

\section{Material and methods}

\subsection{Greenhouse experiment and growing conditions}

The experiments started at the beginning of January 2019, were carried out in the greenhouses of CREA-OF in Pescia (Pt), Tuscany, Italy $\left(43^{\circ} 54^{\prime} \mathrm{N} 10^{\circ} 41^{\prime} \mathrm{E}\right)$ on plants of Portulaca grandiflora (Moss Rose) (Figure 1). The plants were placed in pots $\varnothing 10 \mathrm{~cm} ; 100$ plants for thesis divided into 5 replicas of 20 plants each.

All plants were fertilized with the same amount of nutrients supplied through a controlled release fertilizer [5 kg m${ }^{-3}$ Osmocote Pro® 6 months with $190 \mathrm{~g} / \mathrm{kg}$ of N, $39 \mathrm{~g} / \mathrm{kg}$ of P, $83 \mathrm{~g} / \mathrm{kg}$ of $\mathrm{K}]$ mixed with the growing medium before transplantation.

The 3 experimental groups in cultivation were:

- Group without algae (CTRL), irrigated with water and previously fertilized substrate;

- Group with Spirulina (SPR) and fertilized substrate. (5 g of Spirulina every $20 \mathrm{~L}$ of water, $2 \mathrm{~L}$ of water containing 5:20 mixture Spirulina for every $20 \mathrm{~L}$ of peat);

- Group with Klamath (KLT) and fertilized substrate, 3 g of Klamath every $20 \mathrm{~L}$ of water, $2 \mathrm{~L}$ of water containing 3:20 mixture Klamath for every $20 \mathrm{~L}$ of peat).

The plants have been watered daily and grown for 7 months.

On 25 July 2019, plant height, vegetative and roots weight, leaves, stems and flowers number, flowers diameter and flowering time, Pn (LI-6400XT Portable Photosynthesis System, ten days before the destructive analysis), chlorophyll content (FieldScout CM 1000 Chlorophyll Meter), N,P,K (Kjeldal UDK 169; Jenway 6305016300 visible spectrophotometer) were recorded.

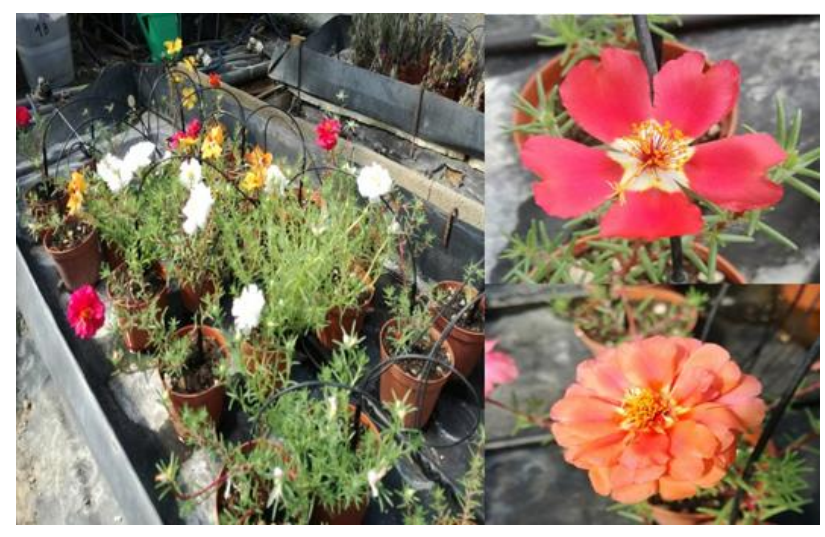

Figure 1 Detail of the flower and greenhouse cultivation of Portulaca grandiflora at CREA-OF (Pescia)

\subsection{Statistics}

The experiment was carried out in a randomized complete block design. Collected data were analyzed by one-way ANOVA, using GLM univariate procedure, to assess significant $(P \leq 0.05,0.01$ and 0.001$)$ differences among 
treatments. Mean values were then separated by LSD multiple-range test $(P=0.05)$. Statistics and graphics were supported by the programs Costat (version 6.451) and Excel (Office 2010).

\section{Results}

\subsection{Plant growth}

The test showed a significant increase in the agronomic parameters analysed in plants treated with Spirulina and Klamath algae. In fact, all the plants treated with (SPR and KLT), showed a significant increase in plant height (Figure $2 \mathrm{~A}$ ) and stems number (Figure 2B), flowers number (Figure 2C) and diameter (Figure 2D), vegetative (Figure 2G) and roots weight (Figure 2E), leaves number (Figure 2H) and flowering time (Figure 2F).
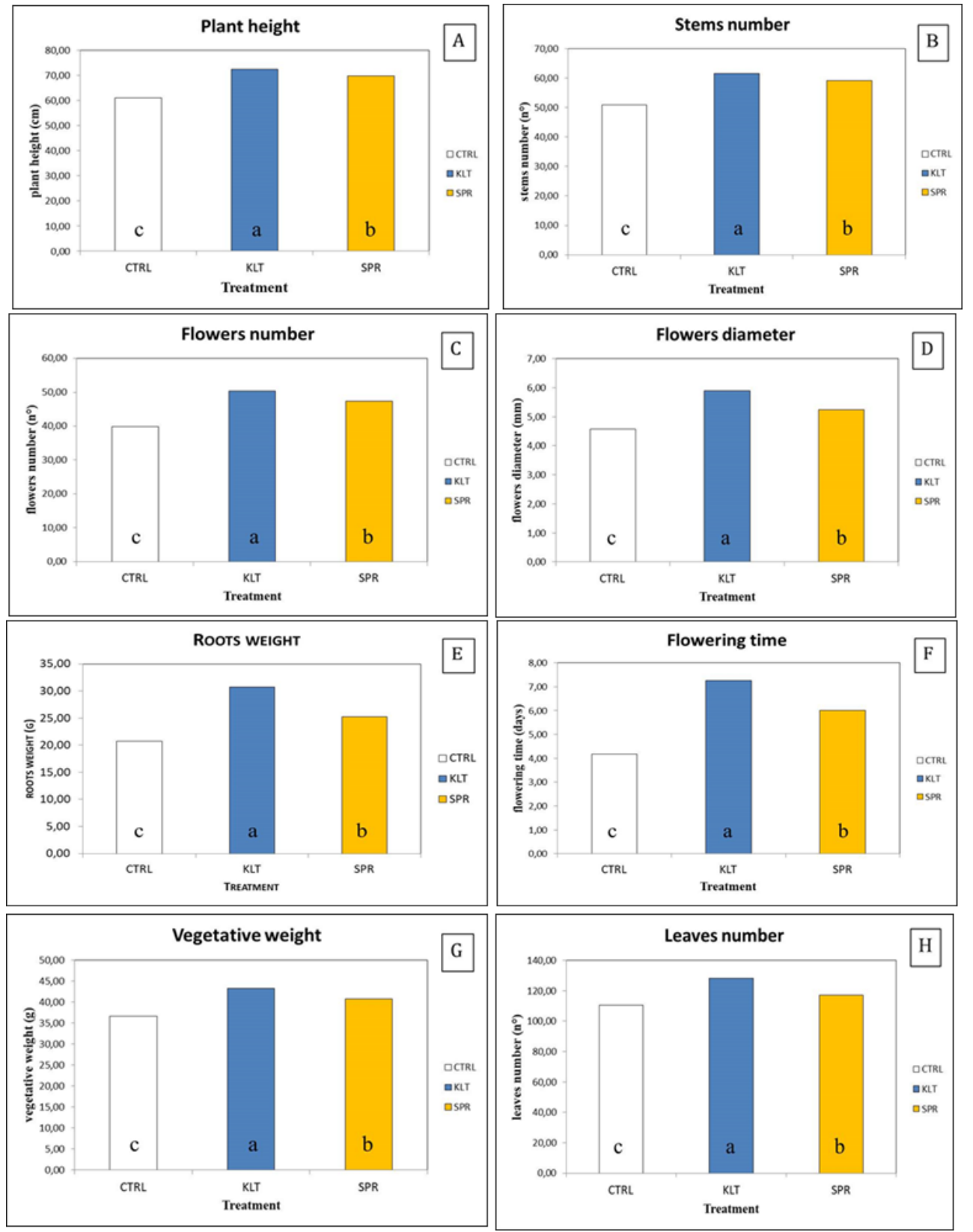

Figure 2 Effect of algae on growth and flowering improvement of Portulaca grandiflora. Legend: (A) plant height; (B) stems number; (C) flowers number; (D) flowers diameter; (E) roots weight; (F) flowering time; (G) vegetative weight; $(\mathrm{H})$ leaves number. Each value reported in the graph is the mean of three replicates \pm standard deviation. Statistical analysis performed through one-way ANOVA. Different letters for the same parameter indicate significant differences according to LSD test $(\mathrm{P}=0.05)$. 
In Portulaca, the height of the plants was $72.40 \mathrm{~cm}$ (KLT), $69.74 \mathrm{~cm}$ (SPR) compared to $61.13 \mathrm{~cm}$ of the control. For the number of stems was found 61.58 (KLT), 59.17 (SPR), 50.92 in (CRLT). There was a significant increase in the number of flowers in (KLT) 50.42 and (SPR) 47.42, compared to 39.92 in the control. Also for the diameter of the flowers same trend: $5.89 \mathrm{~mm}$ in (KLT), $5.24 \mathrm{~mm}$ (SPR) and $4.57 \mathrm{~mm}$ (CRLT).

The test also showed a significant increase in the number of leaves in (KLT) 128.08 and (SPR) 117.17 against 110.58 of the untreated control. There is also a greater floral duration of 7.25 days in (KLT), 6 days in (SPR) compared to 4.17 days of the control.

The weight of vegetative (Figure 3A) and radical biomass (Figure 3B) also increased significantly in the groups treated with Klamath and Spirulina algae: $43.27 \mathrm{~g}$ (KLT), $40.73 \mathrm{~g}$ (SPR) compared to $36.68 \mathrm{~g}$ of the control for the vegetative weight and $30.69 \mathrm{~g}$ (KLT), $25.21 \mathrm{~g}$ (SPR) compared to $20.70 \mathrm{~g}$ of the control for the radical weight.
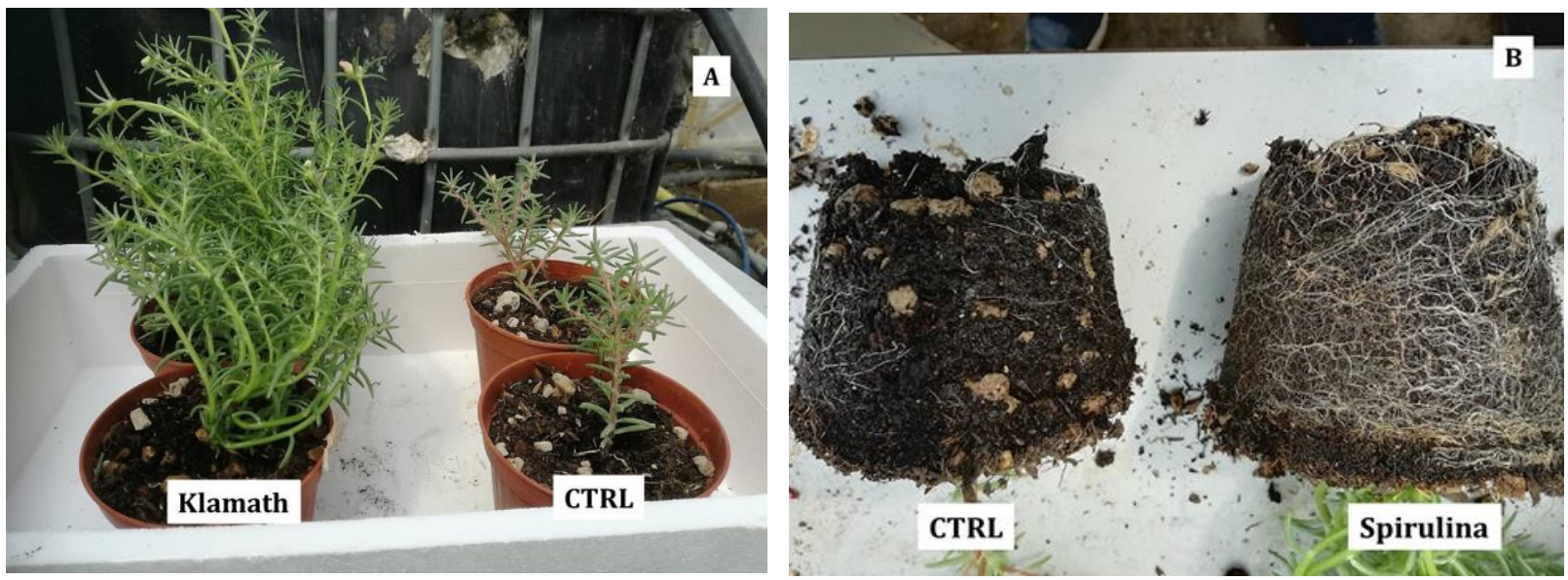

Figure 3 Effect of algae on the vegetative (A) and radical growth (B) of Portulaca grandiflora plants

The test showed that the use of Spirulina and Klamath in the growing medium can significantly influence the germination of portulaca.

With regard to the percentage of germinated seeds, the test showed that the algae Spirulina and Klamath $(92.30 \%$ and $90.60 \%)$ can significantly improve this aspect compared to the untreated control (88.90\%). There is also a significant reduction in the average germination time of 9 and 11 days in (SPR and KLT), compared to 13 days in the control (Table 1).

Table 1 Evaluation of the effect of Spirulina and Klamath algae in the germination of Portulaca grandiflora seeds

\begin{tabular}{lllll}
\hline Groups & Seed germination (\%) & $\begin{array}{l}\text { Average } \\
\text { (days) }\end{array}$ & germination & time \\
\hline CTRL & 88,90 & $13,00 \mathrm{c}$ & \\
SPR & 92,30 & $9,00 \mathrm{a}$ & \\
KLT & 90,60 & $11,00 \mathrm{~b}$ & \\
\hline
\end{tabular}

Each value reported in the graph is the mean of three replicates \pm standard deviation. Statistical analysis performed through one-way ANOVA. Different letters for the same parameter indicate significant differences according to LSD test $(\mathrm{P}=0.05)$.

Table 2 shows how the use of algae such as Spirulina and Klamath can significantly influence photosynthesis, chlorophyll content and mineral absorption of plants. In particular (KLT) and (SPR) 14.46 and $14.27 \mu \mathrm{mol} \mathrm{m}-2 \mathrm{~s}-1$ compared to $11.31 \mu \mathrm{mol} \mathrm{m}-2 \mathrm{~s}-1$ for Pn. A significant increase in the chlorophyll content of 25.08 (SPR), 22.98 (KLT) compared to 19.21 in the untreated control. There is also a significant improvement in the absorption of NPK in the groups treated with the two algae compared to the untreated control, with a better result than the groups with Spirulina. 
Table 2 Evaluation of the effect of Spirulina and Klamath algae on the physiological parameters and mineral absorption of Portulaca grandiflora plants

\begin{tabular}{|c|c|c|c|c|c|}
\hline Groups & 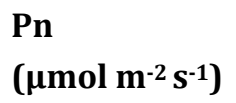 & $\begin{array}{l}\text { Chlorophyll content } \\
\text { (spad index) }\end{array}$ & $\begin{array}{l}N \\
(g / K g)\end{array}$ & $\begin{array}{l}\mathbf{P} \\
(\mathrm{g} / \mathrm{Kg})\end{array}$ & $\begin{array}{l}\mathrm{K} \\
(\mathrm{g} / \mathrm{Kg})\end{array}$ \\
\hline CTRL & $11,31 \mathrm{~b}$ & $19,21 \mathrm{c}$ & $19,05 \mathrm{~b}$ & $1,94 \mathrm{c}$ & $17,42 \mathrm{c}$ \\
\hline SPR & 14,27 a & 25,08 a & $22,15 \mathrm{a}$ & $3,16 \mathrm{~b}$ & $21,88 \mathrm{~b}$ \\
\hline KLT & 14,46 a & $22,98 \mathrm{~b}$ & $22,72 \mathrm{a}$ & $3,51 \mathrm{a}$ & $22,90 \mathrm{a}$ \\
\hline
\end{tabular}

Each value reported in the graph is the mean of three replicates \pm standard deviation. Statistical analysis performed through one-way ANOVA. Different letters for the same parameter indicate significant differences according to LSD test $(\mathrm{P}=0.05)$.

\section{Discussion}

The use of algae in substrates for ornamental plants can have positive effects on plant growth, health status and crop yield, which is normally due to better nutrient uptake.

In fact, algae contain carbohydrates, vitamins, trace hormones and hormone-like substances.

Algae can stimulate the physiological and biochemical processes of plants, or act as helicators, thus determining the production of bioactive substances. In this way, the primary and secondary metabolism can be influenced in the different crops with greater resistance to various biotic and abiotic stresses. Algae extracts can also influence the microflora of the soil and plant growth substrates, promoting root growth and influencing nutrient availability. [10] Algae can positively influence seed germination, root growth, leaf development, vigour and resistance to various abiotic stresses. [11] Algae stimulate root development, increasing the ability to explore roots and absorb nutrients. This results in a stimulation of the primary metabolism with a higher absorption of nutrients. [12] In fact, the test has shown a better radical development of the groups treated with alga Spirulina and Klamath and a significant increase in the absorption of NPK.

The variability of the results can be determined by the heterogeneity of the raw material or by the manufacturing processes and by the type of application that can determine a different physiological response.

Environmental factors (humidity and temperature) can also influence the absorption of the product. When all these conditions are met, algae, as in this experiment, can improve the growth and quality of plants by increasing the efficiency of use of nutrients and an improvement in tolerance to biotic and abiotic stress.

\section{Conclusion}

The test showed that the use of algae (Spirulina and Klamath) can improve the growth and flowering of Portulaca grandiflora plants, in particular by significantly increasing the vegetative and radical part of the plants, the number of flowers, the duration of flowering, the number of stems, leaves and the height of the plants. It also highlights significant improvements in seed germination and plant physiological and mineral absorption parameters. This can be a valuable help for those growers who want to improve the quality of ornamental crops using products that are easy to use and not harmful to the environment.

\section{Compliance with ethical standards}

\section{Acknowledgments}

The article is part of the "Micronaturale" project: alternative techniques to synthetic chemistry for the cultivation and defense of plants. 


\section{References}

[1] Barthlott W and Hunt D. (2000). Seed diversity in the Cactaceae, subfamily Cactoideae (Succulent Plant Research, vol. 5). D. Hunt, Sherborne, UK. 173.

[2] Dalavi J, Deshmukh P, Jadhav V and Yadav S. (2018). Two new species of Portulaca (Portulacaceae) from India. Phytotaxa, 376, 068-076.

[3] Engelmann G. (1850). Portulacaceae. Boston Journal of Natural History, 6, 153-155.

[4] Geesink R. (1969). An account of the genus Portulaca in IndoAustralia and the Pacifi c. Blumea, 17, 275-301.

[5] Legrand CD. (1953). Desmembracion del genero Portulaca I. Comunicaciones Botánicas del Museo de Historia Natural de Montevideo, 31, 1-15.

[6] Sivarajan VV. (1980). Taxonomic notes of the genus Portulaca Linn. from India. Journal of Bombay Natural History Society, 78, 256-260.

[7] Habib MAB, Parvin M, Huntington TCH and Hasan MR. (2008). A Review on culture, production and use of spirulina as food for humans and feeds for domestic animals and fish. Food and Agriculture Organization of The United Nations. Retrieved November 20, 2008, Circular 1034.

[8] Li DM and Qi YZ. (1997) Spirulina industry in China: Present status and future prospects. J Appl Phycol, 9, 25-8.

[9] Wayne W. Carmichael CD and Donald MA. (2000). Harvesting of Aphanizomenon flos-aquae Ralfs ex Born. \& Flah. var. flos-aquae (Cyanobacteria) from Klamath Lake for human dietary use. Journal of Applied Phycology, 12(6), 585-595.

[10] Kuwada K, Wamocho LS, Utamura M, Matsushita I and Ishii T. (2006). Effect of red and green algal extracts on hyphal growth of arbuscular mychorrhizal fungi, and on mychorrhizal development and growth of papaya and passionfruit. Agronomy Journal, 98(5), 1340-1344.

[11] Khan RI, Hafiz IA, Shafique M, Ahmad T, Ahmed I and Qureshi AA. (2018). Effect on pre-harvest foliar application of amino acids and seaweed (Ascophyllum nodosum) extract on growth, yield, and storage life of different bell pepper (Capsicum annum L.) cultivars grown under hydroponic conditions. Journal of Plant Nutrition, 41(18), 2309-2319.

[12] Chouliaras V, Tasioula M, Chatzissavvidis C, Therios I and Tsabolatidou E. (2009). The effects of a seaweed extract in addition to nitrogen and boron fertilization on productivity, fruit maturation, leaf nutritional status and oil quality of the olive (Olea europaea L.) cultivar Koroneiki, Journal of the Science of Food and Agriculture, 89 (6), 984-988.

\section{How to cite this article}

Domenico P. (2019). Possible use of Spirulina and Klamath algae as biostimulants in Portulaca grandiflora (Moss Rose). World Journal of Advanced Research and Reviews, 3(2), 01-06. 